\title{
Phasic and Sustained Fear are Pharmacologically Dissociable in Rats
}

\author{
Leigh Miles*,', Michael Davis² and David Walker ${ }^{2}$ \\ 'Department of Molecular and Systems Pharmacology, Emory University, Atlanta, GA, USA; '2Department of Psychiatry and Behavioral Sciences, \\ Center for Behavioral Neuroscience, Yerkes National Primate Center, Emory University, Atlanta, GA, USA
}

\begin{abstract}
Previous findings suggest differences in the neuroanatomical substrates of short- (seconds) vs longer-duration (minutes) fear responses. We now report that phasic and sustained fear can also be differentiated pharmacologically, based on their response to several treatments that either are or are not clinically effective anxiolytics. For these experiments, short- or long-duration clicker stimuli were paired with footshock. Acoustic startle amplitude was later measured in the absence of the clicker, or within seconds (phasic fear) or minutes (sustained fear) of its onset. Before testing, rats received a single injection of vehicle, the benzodiazepine chlordiazepoxide, the $5 \mathrm{HT}$ IA agonist and dopamine D2 antagonist buspirone, the selective serotonin reuptake inhibitor fluoxetine, or a 3-week treatment with either vehicle or fluoxetine. Chlordiazepoxide blocked sustained, but not phasic startle increases. Acute buspirone, which is not anxiolytic in human beings, did not affect sustained startle increases, but did disrupt phasic increases. Chronic fluoxetine blocked sustained startle increases and unreliably reduced phasic increases; acute fluoxetine affected neither. The results indicate that phasic and sustained fear responses can be pharmacologically dissociated, further validating this distinction, and suggest that sustained startle increases may be especially useful as anxiety models and anxiolytic screens.

Neuropsychopharmacology (20 I I) 36, I563-1574; doi: I0.1038/npp.20 I 1.29; published online 6 April 20I I
\end{abstract}

Keywords: startle; SSRIs; fluoxetine; buspirone; benzodiazepine; bed nucleus stria terminalis

\section{INTRODUCTION}

A major aim of psychiatric research is to better understand the neural mechanisms of psychiatric disorders, including anxiety. Because the physiological symptoms of healthy fear and clinical anxiety are highly similar, and because it is generally believed that clinical anxiety reflects maladaptive activity within fear circuitry, experimentally induced fear in healthy controls and in research animals has been used extensively to pursue this goal.

We have used changes in the amplitude of the acoustic startle reflex as a fear measure and anxiety surrogate (Davis, 1986), and have described the neural circuitry that mediates this effect (cf, Davis, 2006). When evoked by brief presentations of stimuli previously paired with shock, fearpotentiated startle is mediated by direct and indirect projections from the medial central nucleus of the amygdala (CeA) to the primary startle reflex pathway in the pontine reticular formation (Hitchcock and Davis, 1991; Rosen et al,

*Correspondence: L Miles, Department of Molecular and Systems Pharmacology, Emory University, Yerkes Neuroscience Building, Room 5222, 954 Gatewood Road NE, Atlanta, GA 30329, USA, Tel: + I 404 7273587 or + | 40472737 II, Fax: + | 4047278070 ,

E-mail: lamiles@emory.edu

Received 8 October 2010; revised 8 February 2011; accepted 9 February 2011
1991; Meloni and Davis, 1999; Zhao and Davis, 2004). However, when evoked by other treatments, including intracerebroventricular infusions of the stress-related peptide corticotropin-releasing factor (Lee and Davis, 1997), by startle testing in illuminated $v s$ darkened test chambers (Walker and Davis, 1997b), or by repeated footshock stress (Gewirtz et al, 1998), such increases appear to be mediated not by the medial CeA, but instead by a more rostral extension of the extended amygdala known as the bed nucleus of the stria terminalis (BNST).

In reviewing these and possibly related findings from other laboratories (eg, Hammack et al, 2004; Sullivan et al, 2004; Waddell et al, 2006), we have noted that CeA manipulations more consistently disrupt short-duration, rapid-onset/offset fear responses to distinct and imminent threats (phasic fear), whereas BNST manipulations more consistently disrupt longer-duration responses to more sustained stimuli (cf, Walker et al, 2009b).

To explicitly compare the neurobiological substrates of phasic $v s$ sustained startle increases, and to further evaluate the validity of this distinction, we developed a modified conditioned fear-potentiated startle paradigm in which clicker stimuli of variable duration (from $3 \mathrm{~s}$ to $8 \mathrm{~min}$ ) are paired with co-terminating footshocks. During testing, rats are presented with startle-eliciting noise bursts delivered within seconds (for phasic fear testing) or minutes (for sustained fear testing) of 
conditioned stimulus (CS) onset. In this study, we used this paradigm to compare the effect on phasic and sustained fear of several pharmacological treatments that are clinically useful for anxiety reduction (ie, acute chlordiazepoxide, chronic fluoxetine) and others that are not (ie, acute buspirone, acute fluoxetine). We discuss the results with respect to their implications for the validity of the phasic $v s$ sustained fear distinction, and for the utility of phasic $v s$ sustained fear procedures as anxiety models and anxiolytic screens.

\section{MATERIALS AND METHODS}

\section{Animals}

Male Sprague-Dawley rats (200-250g at arrival; Charles River, Raleigh, NC) were housed four per cage on a 12-h light-dark cycle in a temperature- and humidity-controlled room with food and water freely available. Behavioral procedures began approximately 1 week after arrival, and were conducted in accordance with USDA, NIH, and Emory University guidelines.

\section{Apparatus}

Rats were trained and tested in $8 \times 15 \times 15 \mathrm{~cm}$ Plexiglas and wire mesh cages with four $6.0-\mathrm{mm}$ diameter stainless-steel floorbars, located within a sound-attenuated behavior chamber. Startle responses were evoked by 50 -ms ( $95 \mathrm{~dB})$ white-noise bursts generated by a computer sound file, amplified by a Radio Shack amplifier (Tandy, Fort Worth, TX), and delivered through Radio Shack Supertweeter speakers located in front of the cage. The same speakers delivered background noise $(60 \mathrm{~dB}, 1-20 \mathrm{kHz})$ provided by an ACO Pacific (Belmont, CA, USA) noise generator. All sound level measurements were made from the center of the cage.

Startle amplitude and shock reactivity were quantified using a PCB Piezotronics (Depew, NY, USA) accelerometer affixed to the bottom of the cage. The accelerometer produces a voltage output proportional to the velocity of cage movement (eg, produced by the rats' startle response), which was integrated by a PCB Piezotronics signal conditioner and digitized by a GW Instruments (Somerville, MA) InstruNet device. Startle amplitude was defined as the maximum peak-to-peak voltage during the first $200 \mathrm{~ms}$ after each noise burst. Shock responses were similarly quantified, using a 500-ms window concurrent with shock delivery.

The CS was a $70-\mathrm{dB}, 60-\mathrm{Hz}$ clicker stimulus delivered through speakers located behind each chamber. The unconditioned stimulus was a $0.5-\mathrm{s}, 0.35-\mathrm{mA}$ footshock delivered through the floor bars. The sequencing of all stimuli was controlled by a desktop computer using custom-designed software (The Experimenter; Glass Bead Software, New Haven, CT).

\section{Behavioral Procedures}

Experimental sequence. Rats received two acclimation sessions (days 1 and 2), followed by a pre-conditioning test for sustained or phasic fear (day 3), followed by three conditioning sessions (days 4-6), and followed $48 \mathrm{~h}$ later by a post-conditioning test. Thus, some rats were tested for sustained and others for phasic fear, but all rats received the same conditioning procedure. These procedures are described below, and presented graphically in Figure 1.

Acclimation. Rats were placed into the test cage and, after $5 \mathrm{~min}$, presented with the first of 48 startle-eliciting whitenoise bursts (inter-stimulus interval $($ ISI $)=30 \mathrm{~s}$ ).

Pre-conditioning sustained fear test. Rats were placed into the test cage and, after $5 \mathrm{~min}$, presented with the first of 32 startle-eliciting noise bursts (ISI $=30 \mathrm{~s}$ ). The first 16 were presented in the absence, and the next 16 in the presence of a $60-\mathrm{Hz}$ clicker stimulus.

Pre-conditioning phasic fear test. Rats were placed into the test cage and, after $5 \mathrm{~min}$, presented with the first of 75 startleeliciting noise bursts (ISI $=30 \mathrm{~s}$ ). Thirty of the final 60 were presented $3.2 \mathrm{~s}$ after the onset of a 3.7-s clicker stimulus and another 30 (intermixed) were presented in its absence.

Fear conditioning. On each conditioning day, rats received eight presentations of variable-duration clicker stimuli (3-, 10-, and 20-s; 1-, 2-, 4-, 6-, and 8-min), each co-terminating with footshock. The first CS of each session occurred $5 \mathrm{~min}$ after the rat was placed into the conditioning chamber. The interval between offset of one CS and onset of the next was $3 \mathrm{~min}$. During the first conditioning session, the clicker stimuli were presented in the order of increasing duration. During the second and third, they were sequenced randomly.

Post-conditioning phasic and sustained fear tests. Rats were tested after conditioning, using procedures identical to those described for the pre-conditioning tests.

Context manipulations. During conditioning, a cotton gauze pad wetted with $0.4 \mathrm{ml}$ of $70 \%$ ethanol solution was placed in front of the test cage. A fluorescent light placed behind the cage ( $150 \mathrm{~lx}$ as measured from the middle of the cage) provided constant illumination. During testing, to minimize context-potentiated startle, the cage was dark and no explicit olfactory stimuli were introduced. In addition, two $5-\mathrm{cm}$ chains hung from the top of the test cage and a sandpaper insert was placed over the floorbars. We have previously found similar changes to be effective in producing discriminable contexts (McNish et al, 1997).

\section{Statistical Analyses}

Sustained fear. Each rat tested for sustained fear received a sustained fear-potentiated startle score. Because our analysis of the control data set indicated that the first startle response after CS onset was markedly higher than all those that followed, and that sustained fear diminished with time, becoming unreliable after approximately the fourth minute of CS presentation (see Figure 2), we calculated a sustained fear-potentiated startle score by dividing mean startle amplitude during the first $4 \mathrm{~min}$ of the CS (beginning with the second CS test trial) by the mean startle amplitude during the last $4 \mathrm{~min}$ of the pre-CS period (see Figure 2). For presentation purposes, these ratios were converted to percent change scores. 


\section{a Sustained Fear Procedure}

Acclimation

60-dB Background White Noise (black lines)

in Context $\mathrm{A}$

Pre-conditioning Test

in Context A

70-dB 60- $\mathrm{Hz}$ Clicker Presentation (gray lines)
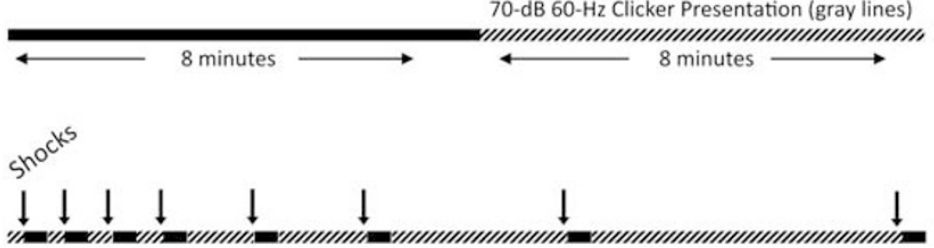

3 Days of Conditioning

in Context B

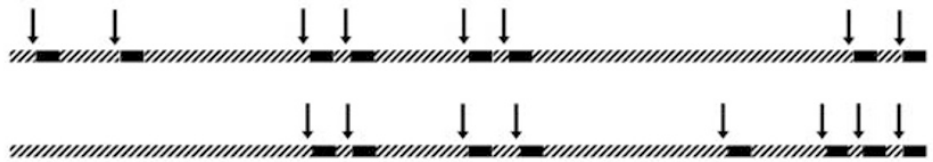

Post-conditioning Test

in Context A

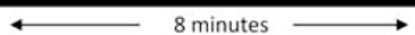

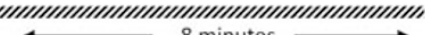

b Phasic Fear Procedure

Acclimation

in Context $\mathrm{A}$
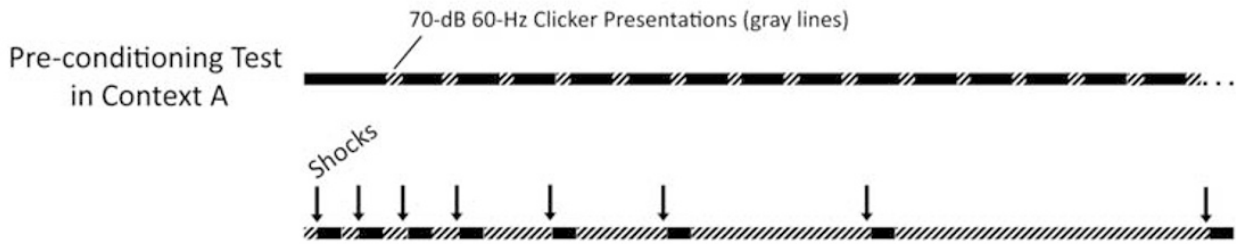

3 Days of Conditioning

in Context B

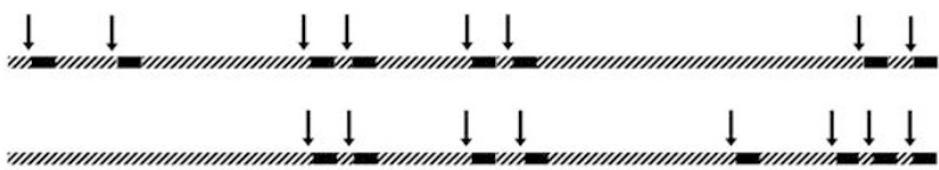

Post-conditioning Test

in Context A

Figure I Behavioral procedures and timeline. Acclimation, a pre-conditioning test, each of three conditioning sessions in which clicker stimuli (gray) of variable duration were paired with co-terminating footshock (arrows), and a post-conditioning test, took place on separate days. With the exception of testing, the sustained and phasic fear procedures were identical. For sustained fear testing, startle was measured before and then during presentation of an 8-min clicker stimulus. For phasic fear testing, startle was measured in the presence and in the absence, on intermixed test trials, of 3.7-s clicker stimuli. Session and event lengths are not drawn to scale. For a detailed description, see the Materials and Methods section. Panel (a) Sustained Fear Procedure. Panel (b) Phasic Fear Procedure.

Phasic fear measure 1. Each rat tested for phasic fear received a phasic fear-potentiated startle score, defined as the ratio between the mean startle amplitude of all CS test trials and the mean startle amplitude of all intermixed non-CS test trials. For presentation purposes, these ratios were converted to percent change scores.

Phasic fear measure 2. An additional measure of phasic fear was computed for rats that received sustained fear testing. This was defined as the ratio between startle amplitude to the very first noise burst after CS onset (ie, on trial 17 that occurred $19.2 \mathrm{~s}$ after CS onset) and the preCS baseline (ie, trials 9-16).

For all measures, we used ratio rather than absolute difference (ie, startle in the presence of clicker-startle in the absence of clicker), because we have previously found that when fear levels remain constant, ratio, but not difference scores remain stable as well (Walker and Davis, 2002b). We also note that our use of startle responses elicited $19.2 \mathrm{~s}$ or less as opposed to $49.2 \mathrm{~s}$ or more, for phasic and sustained fear respectively, is somewhat arbitrary (as would almost certainly be true for any specific time point), as the transition from one to the other is most likely gradual rather than abrupt. Our aim here was to have one set of measures that was more phasic and less sustained than the other, but we recognize that each may have elements of both. As will be seen from the results that follow, the data obtained with these scoring methods generally appear to confirm their validity. 


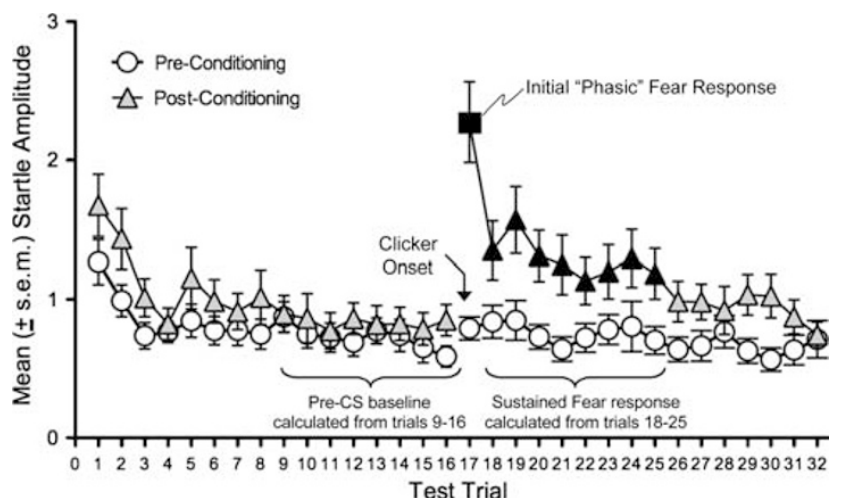

Figure 2 The trial-by-trial raw startle data during conditioning. The raw startle data for all control rats used in these studies is plotted for both the pre- (open circles) and post- (filled square and triangles) conditioning test sessions. Startle responses were evoked every 30 s during the 8 min before CS onset (trials 1-16) and for the $8 \mathrm{~min}$ during which the CS was presented (trials 17-32). Before conditioning, there was little if any effect of the $60-\mathrm{Hz}$ clicker stimulus on startle. After conditioning, potentiation by the clicker CS was clearly evident and especially pronounced on the first test trial after CS onset (ie, trial 17, filled square), which we consider more akin to phasic than sustained fear. Potentiation dropped precipitously from the first to the second CS test trial and more gradually thereafter, becoming statistically unreliable approximately halfway through the $8 \mathrm{~min}$ CS. $\boldsymbol{\Delta}=$ $p<0.05$ for each individual trial vs pre-CS baseline. The percent change scores illustrated in the following figures are based on the ratio (mean startle amplitude across CS test trials 18-25/mean startle amplitude across pre-CS test trials 9-16) for sustained fear, and (mean startle amplitude on trial 17/mean startle amplitude across pre-CS test trials 9-16) for phasic fear measure 2 .

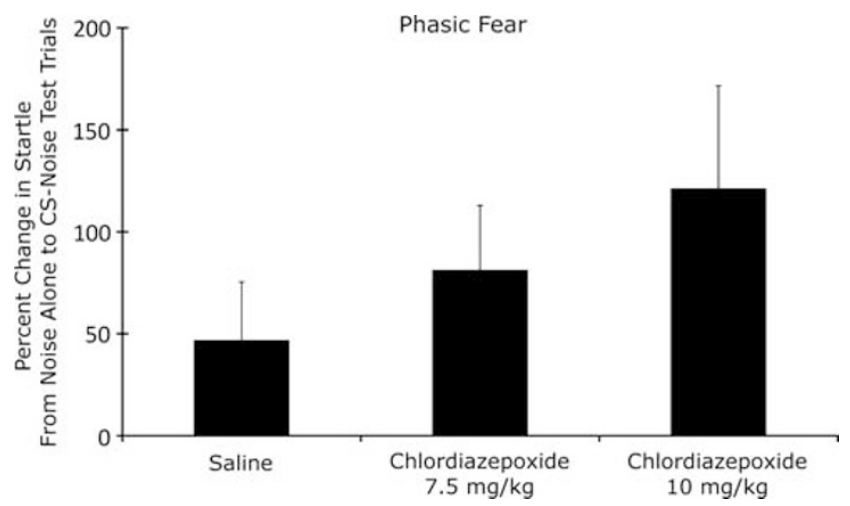

Figure 3 Pre-test chlordiazepoxide did not disrupt phasic startle potentiation to $3.7-$ sec clicker stimuli.

Exclusion criteria. Fear conditioning requires that rats perceive the aversive stimulus. Therefore, we excluded from further analysis the data obtained from rats with footshock reactions of 1.0 or less (the mean of all rats was 3.5) on 12 or more of the 24 conditioning trials. The potentiation data from control rats validated this criterion. Thus, for sustained fear, the mean $( \pm S E M)$ fear-potentiated startle score of rats exceeding this threshold was $83.1 \pm 19.5 \%$ $(N=55) v s 11.5 \pm 16.4 \%$ for those that did not $(N=12)$. For the phasic fear experiments, the mean fear-potentiated startle score of shock-responsive rats was $107.7 \pm 38.9$ $(N=21) v s-26 \pm 23.4(N=3)$ for excluded rats.

Also, because meaningful ratios cannot be calculated for rats that do not show a baseline startle response, the

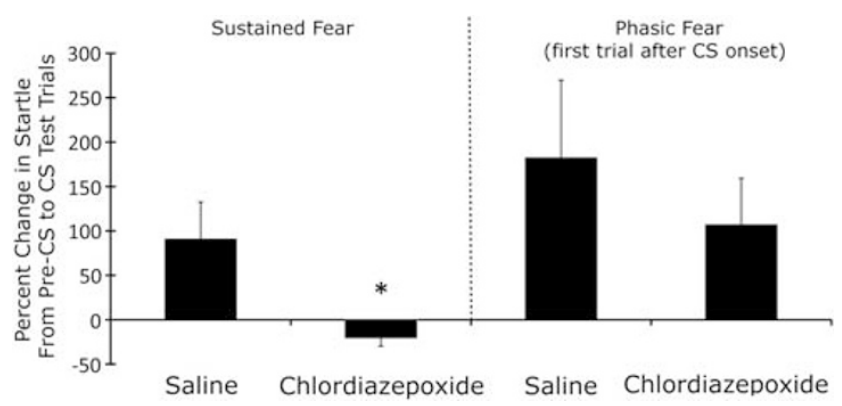

Figure 4 Pre-test chlordiazepoxide $(10 \mathrm{mg} / \mathrm{kg}$, i.p.) blocked sustained startle potentiation, but not the initial potentiation to the first startle stimulus after $\mathrm{CS}$ onset. ${ }^{*}=p<0.05$ vs saline.

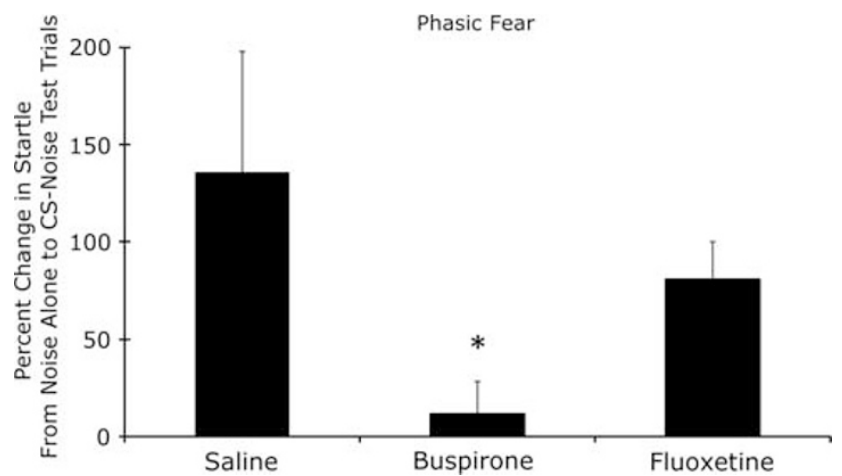

Figure 5 Pre-test buspirone ( $5 \mathrm{mg} / \mathrm{kg}$, s.c.), but not fluoxetine ( $10 \mathrm{mg} / \mathrm{kg}$, i.p.), disrupted startle increases to 3.7-second clicker presentations. High variance in the saline group, and the modest difference versus the fluoxetine group, was largely attributable to a single outlier with a fear-potentiated startle score of $826 \%$. Without this rat, the mean ( \pm s.e.m.) for the saline group was $71.8 \pm 12.9$. $*=p<0.05$ vs saline (with outlier included).

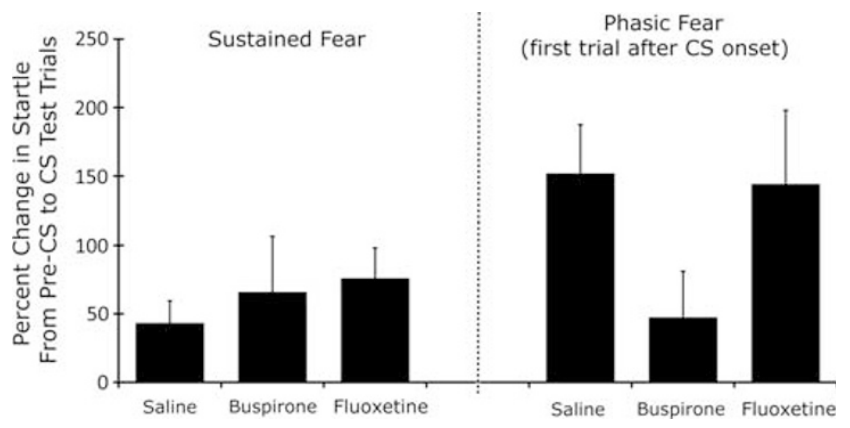

Figure 6 Neither buspirone nor fluoxetine (single injection) disrupted sustained startle increases. The lower level of phasic potentiation in the buspirone compared to saline group was roughly comparable to that seen in Experiment 4, but did not reach significance in this experiment when corrected for multiple comparisons.

data from rats with a mean accelerometer output of $\leqslant 0.1$ (ie, what we observe when cage output is sampled in nonstartled rats) on baseline test trials were also excluded. Only two rats failed to meet this criterion. Both had received chlordiazepoxide before sustained fear testing.

Inferential statistics. The primary analyses were betweengroup comparisons of fear-potentiated scores. Because D'Agostino and Pearson omnibus normality tests indicated significant deviations from normality for both the sustained 


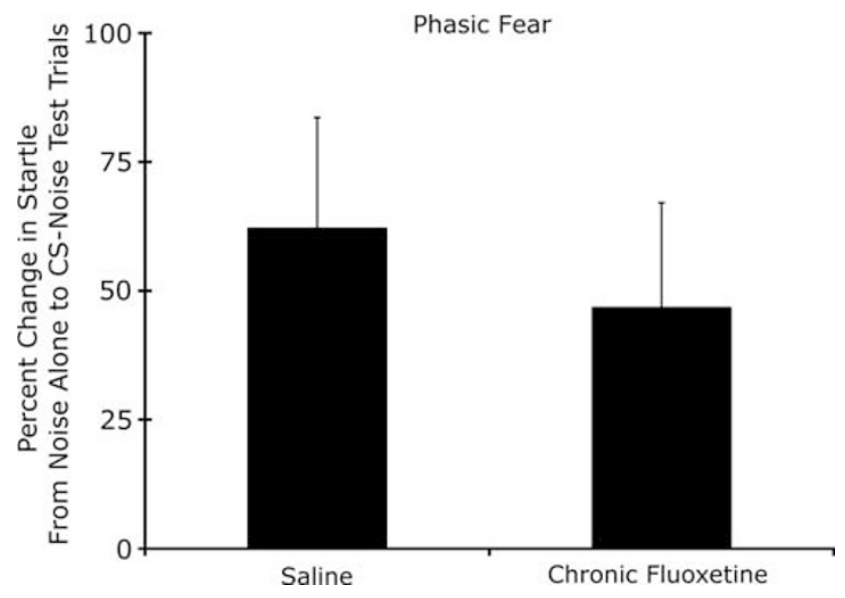

Figure 7 Chronic fluoxetine $(10 \mathrm{mg} / \mathrm{kg}$, p.o., for 21 days beginning approximately 3 hours after the final conditioning session) did not significantly affect startle amplitude increases to phasically-presented fear stimuli.

$(K 2=51.78)$ and phasic fear $(K 2=45.53)$ data sets, and because Grubb's test identified several outliers, betweengroup differences were evaluated using distribution-free (non-parametric) Mann-Whitney or Kruskal-Wallis tests, and also, to establish statistical robustness, by using $t$-tests and ANOVA on log-transformed scores (see Keene (1995)). Follow-up comparisons were made using Dunn's (nonparametric) or Dunnett's $t$-test (parametric) for multiple comparisons with a control. Other analyses intended to address specific questions or issues are included where relevant. For all tests, the criterion for significance was 0.05 (two-tailed).

\section{Procedures Specific to Individual Experiments}

Experiment 1: No-shock control. Because the sustained fear procedure is new, we wished to determine if the clickerinduced startle changes observed in control rats were indeed due to conditioning. To this end, 12 rats underwent the sustained fear procedure exactly as described above, but without shock administration during clicker presentations.

Experiment 2: Acute benzodiazepine effect on phasic fearpotentiated startle. At $10 \mathrm{~min}$ before the post-conditioning test, rats received an intra-peritoneal (i.p.) injection of either saline $(N=5), 7.5 \mathrm{mg} / \mathrm{kg}$ chlordiazepoxide $(N=6)$, or $10 \mathrm{mg} / \mathrm{kg}$ chlordiazepoxide $(N=5)$. Chlordiazepoxide was obtained from Sigma-Aldrich Chemical (St Louis, MO).

For this and all other acute drug administration experiments, rats received the same drug and dose before the preconditioning test, which allowed us to evaluate drug effects on unconditioned startle amplitude. The sole exception was rats that received $7.5 \mathrm{mg} / \mathrm{kg}$ chlordiazepoxide before the post-conditioning test, but $2.5 \mathrm{mg} / \mathrm{kg}$ before the preconditioning test (we had anticipated using $2.5 \mathrm{mg} / \mathrm{kg}$ before both, but increased to the higher dose based on the initial potentiation data from rats that received $10 \mathrm{mg} / \mathrm{kg}$ chlordiazepoxide).

For all experiments, drugs were administered at $0.1 \mathrm{ml}$ saline/100 g body weight.

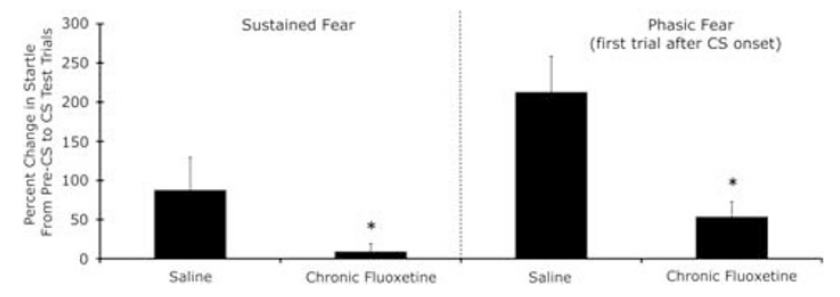

Figure 8 Chronic fluoxetine $(10 \mathrm{mg} / \mathrm{kg}$, p.o., for 21 days beginning approximately 3 hours after the final conditioning session) blocked the sustained increase in startle and significantly attenuated the phasic increase (i.e., the first startle probe after CS onset). ${ }^{*}=p<0.05$ vs saline.

Experiment 3: Acute benzodiazepine effects on sustained fear-potentiated startle. At $10 \mathrm{~min}$ before the pre- and post-conditioning tests, rats received an i.p. injection of saline $(N=12)$ or chlordiazepoxide $(N=11 ; 10 \mathrm{mg} / \mathrm{kg})$.

Experiment 4: Acute buspirone and fluoxetine effects on phasic fear-potentiated startle. At $10 \mathrm{~min}$ before the preand post-conditioning tests, rats received a subcutaneous (s.c.) injection of buspirone $(N=7 ; 5 \mathrm{mg} / \mathrm{kg}$; Sigma-Aldrich Chemical), an i.p. injection of fluoxetine $(N=16 ; 10 \mathrm{mg} / \mathrm{kg}$; Spectrum Chemical, Gardena, CA), or saline $(N=6$, i.p.; $N=7$, s.c.).

Experiment 5: Acute buspirone and fluoxetine effects on sustained fear-potentiated startle. At $10 \mathrm{~min}$ before the pre- and post-conditioning tests, rats received buspirone $(N=13 ; 5 \mathrm{mg} / \mathrm{kg}$, s.c. $)$, fluoxetine $(N=22 ; 10 \mathrm{mg} / \mathrm{kg}$, i.p. $)$, or saline $(N=13$, i.p.; $N=12$, s.c. $)$.

Experiment 6: Chronic fluoxetine effects on phasic fearpotentiated startle. Rats received the first of 21 treatments of either saline $(N=8)$ or fluoxetine $(N=7 ; 10 \mathrm{mg} / \mathrm{kg})$ by oral gavage approximately $3 \mathrm{~h}$ after the final conditioning session and for each of the following 20 days. The postconditioning test was conducted approximately $24 \mathrm{~h}$ after the final injection.

Experiment 7: Chronic fluoxetine effects on sustained fear-potentiated startle. Rats received the first of 21 treatments of saline $(N=18)$ or fluoxetine $(N=20 ; 10 \mathrm{mg} /$ $\mathrm{kg}$ ) by oral gavage approximately $3 \mathrm{~h}$ after the final conditioning session and for each of the following 20 days. The post-conditioning test was conducted approximately $24 \mathrm{~h}$ after the final injection.

\section{RESULTS}

\section{Sustained Fear in Control Animals}

Before presenting results from the individual experiments, we first provide a descriptive account of sustained fear in control rats, as we have not previously presented results from this paradigm. Figure 2 illustrates the trial-by-trial data pooled from all control rats used in the sustained fear experiments. As shown in this figure, startle amplitude mostly habituated to a stable baseline within the first few trials of the pre-CS conditioning phase and remained relatively stable thereafter. Introduction of the clicker 
stimulus, between trials 16 and 17 , had little if any effect on startle before conditioning (open circles), but caused a marked enhancement of startle after conditioning (filled square and triangles). This enhancement was especially pronounced on the first trial after CS onset (trial 17), which we have scored independently as an ancillary measure of phasic fear (ie, phasic fear measure 2). By the fifth minute after CS onset, potentiation began to wane and was no longer statistically reliable.

Figure 2 also shows a modest increase in pre-CS startle amplitude from the pre- to post-conditioning test. Although significant overall ANOVA on the first 16 trials that preceded CS onset indicated a main effect of Session (ie, pre- $v s$ post-conditioning), $\mathrm{F}(1,51)=8.54, p<0.05$, the increase was only observed in rats from Experiment 7-that is, the group that had a 25-day delay interposed between the two tests (see also Table 1). As such, we believe this increase most likely reflects weight gain or something associated with the daily gavage procedure, as opposed, for example, to a generalized context fear response.

The figures that follow show percent change (ie, from non-CS or pre-CS test trials to CS test trials) scores only. The absolute startle amplitudes from which these change scores are derived are provided in Table 1.

Experiment 1: Clicker-induced startle changes require conditioning. During testing, rats that did not receive clicker-shock pairings did not show either phasic or sustained startle increases (see Table 1).

Experiment 2: Pre-test chlordiazepoxide did not disrupt phasic startle potentiation. Phasic fear potentiation was not reduced, but was nominally (although not significantly) greater in the chlordiazepoxide compared with saline groups (Figure 3) based on ANOVA. Baseline startle was reduced, however, as indicated by a significant Group effect, $\mathrm{F}(2,13)=4.40$. A Dunnett's $t$-test indicated a significant baseline difference between the vehicle and $10 \mathrm{mg} / \mathrm{kg}$ group, $q(9)=2.95$, but not between the 0 and $7.5 \mathrm{mg} / \mathrm{kg}$ group (see also Table 1).

Experiment 3: Pre-test chlordiazepoxide blocked the sustained, but not initial component of startle potentiation. As shown in Figure 4 (and see also Table 1), acute pre-test chlordiazepoxide administration blocked startle increases to the long-duration clicker CS. The disruption was statistically robust, being detected by parametric, $t(21)=3.15$, as well as non-parametric, $U=23$, analyses. When limited to the first startle response after CS onset (phasic fear measure 2), a betweengroup difference was not found using either analysis. There were no between-group differences in baseline startle.

Experiment 4: Pre-test buspirone, but not fluoxetine (single injection) blocked phasic startle potentiation. ANOVA on the log-transformed scores indicated a significant Treatment effect, $\mathrm{F}(2,33)=4.25$, which was due to the difference between the saline and buspirone groups, $q(18)=2.87$ (Dunnett's $t$-test). Non-parametric analyses yielded essentially the same results. Thus, a Kruskal-Wallis comparison also indicated significant between-group differences, $H=7.74$, with Dunn's multiple comparison test indicating a significant difference between the saline and buspirone groups (rank sum difference $=13.21$ ), but not between the saline and acute fluoxetine groups. These results are shown in Figure 5. ANOVA also indicated a significant Group effect on baseline startle, $\mathrm{F}(2,33)=4.80$. Dunnett's $t$-test indicated a significant difference between the saline and buspirone groups, $q(18)=3.09$, but not between the saline and fluoxetine groups (see Table 1).

Experiment 5: Neither buspirone nor acute fluoxetine blocked sustained startle potentiation. These results are shown in Figure 6 (and see also Table 1). As in the preceding experiment, phasic potentiation was markedly lower in the buspirone compared with saline groups (ie, using the first startle response after CS onset as a supplemental phasic fear measure) -in this case, $47 \pm 34$ vs $152 \pm 35 \%$, respectively - but this was not statistically significant using either ANOVA or Kruskal-Wallis analyses. The between-group difference with respect to baseline startle was also comparable to the preceding experiment and this was significant, $\mathrm{F}(2,57)=4.91$. As before, this was due to a higher baseline in the buspirone group compared with saline group, $q(18)=2.47$, Dunnett's $t$-test, which we have found previously (Kehne et al, 1988).

Experiment 6: Chronic fluoxetine does not affect startle increases to phasically presented fear stimuli. Neither Mann-Whitney nor $t$-test analyses indicated significant between-group differences ( $p>0.05$ for both). Baseline startle was similarly unaffected. These results are shown in Figure 7 (and see also Table 1).

Experiment 7: Chronic fluoxetine disrupts startle increases to a sustained fear stimulus. As shown in Figure 8 and confirmed statistically by an independent-samples $t$-test on the log-transformed scores, $t(36)=2.69$, as well as Mann-Whitney analysis of percent change scores $(U=99)$, chronic fluoxetine significantly disrupted startle increases to the sustained fear stimulus. Fluoxetine also significantly reduced fear-potentiated startle to the first startle stimulus after CS onset (phasic fear measure 2), $t(36)=1.71$ and $U=125$. Baseline startle was significantly greater in the fluoxetine group, $t(36)=2.27$.

\section{DISCUSSION}

We evaluated the effects on phasic and sustained startle increases of several pharmacological treatments that either are or are not clinically effective for anxiety reduction. Phasic and sustained startle increases responded differently, and in opposite directions to several of these treatments, lending support to the validity of the distinction. Moreover, the specific pattern of results suggested that sustained startle increases may have greater predictive validity, and might therefore be more useful, as an animal model of clinical anxiety, than phasic startle increases. The results obtained with each compound are discussed in turn below. 
Table I Mean Startle Amplitude $( \pm$ SEM) in Arbitrary Units on a Linear Scale, Together with Log-Transformed FPS Scores

\begin{tabular}{|c|c|c|c|c|c|c|c|c|c|c|}
\hline & \multicolumn{5}{|c|}{ Pre-conditioning test } & \multicolumn{5}{|c|}{ Post-conditioning test } \\
\hline & $\begin{array}{l}\text { Startle } \\
\text { without } \\
\text { clicker }\end{array}$ & $\begin{array}{c}\text { Startle } \\
\text { with clicker } \\
\text { (phasic) }\end{array}$ & $\begin{array}{l}\text { Startle with } \\
\text { clicker } \\
\text { (sustained) }\end{array}$ & $\begin{array}{c}\text { Log-transformed } \\
\text { phasic } \\
\text { FPS }^{\mathbf{a}}\end{array}$ & $\begin{array}{l}\text { Log-transformed } \\
\text { sustained } \\
\text { FPS }\end{array}$ & $\begin{array}{l}\text { Startle } \\
\text { without } \\
\text { clicker }\end{array}$ & $\begin{array}{l}\text { Startle with } \\
\text { clicker } \\
\text { (phasic) }\end{array}$ & $\begin{array}{l}\text { Startle with } \\
\text { clicker } \\
\text { (sustained) }\end{array}$ & $\begin{array}{c}\text { Log-transformed } \\
\text { phasic } \\
\text { FPS }^{\mathrm{a}}\end{array}$ & $\begin{array}{l}\text { Log-transformed } \\
\text { sustained } \\
\text { FPS }\end{array}$ \\
\hline \multicolumn{11}{|l|}{ Sustained fear tests ${ }^{\mathrm{a}}$} \\
\hline \multicolumn{11}{|l|}{ Experiment I } \\
\hline No shock control & $0.64 \pm 0.09$ & $0.61 \pm 0.10$ & $0.76 \pm 0.11$ & $-0.03 \pm 0.08$ & $0.08 \pm 0.05$ & $0.56 \pm 0.18$ & $0.47 \pm 0.08$ & $0.49 \pm 0.07$ & $-0.05 \pm 0.06$ & $-0.05 \pm 0.06$ \\
\hline \multicolumn{11}{|l|}{ Experiment 3} \\
\hline Acute saline & $0.75 \pm 0.19$ & $0.69 \pm 0.13$ & $0.83 \pm 0.24$ & $0.01 \pm 0.06$ & $-0.03 \pm 0.05$ & $0.58 \pm 0.16$ & $1.66 \pm 0.72$ & $0.74 \pm 0.19$ & $0.25 \pm 0.14$ & $0.19 \pm 0.09$ \\
\hline Acute chlordiazepoxide & $0.79 \pm 0.32$ & $0.52 \pm 0.14$ & $1.0 \pm 0.33$ & $-0.08 \pm 0.15$ & $0.16 \pm 0.08$ & $0.80 \pm 0.29$ & $1.72 \pm 0.86$ & $0.58 \pm 0.27$ & $0.22 \pm 0.09$ & $-0.13 \pm 0.05$ \\
\hline \multicolumn{11}{|l|}{ Experiment 5} \\
\hline Acute saline & $0.73 \pm 0.12$ & $0.88 \pm 0.15$ & $0.79 \pm 0.13$ & $0.05 \pm 0.07$ & $0.02 \pm 0.04$ & $0.80 \pm 0.13$ & $1.74 \pm 0.35$ & $1.07 \pm 0.20$ & $0.29 \pm 0.07$ & $0.10 \pm 0.05$ \\
\hline Acute buspirone & $1.39 \pm 0.24$ & $1.62 \pm 0.30$ & $1.43 \pm 0.27$ & $0.06 \pm 0.06$ & $-0.01 \pm 0.09$ & $1.40 \pm 0.31$ & $1.34 \pm 0.23$ & $1.73 \pm 0.32$ & $0.05 \pm 0.10$ & $0.12 \pm 0.08$ \\
\hline Acute fluoxetine & $0.80 \pm 0.16$ & $0.94 \pm 0.17$ & $0.81 \pm 0.11$ & $0.06 \pm 0.08$ & $0.02 \pm 0.05$ & $0.63 \pm 0.11$ & $1.25 \pm 0.26$ & $0.97 \pm 0.18$ & $0.21 \pm 0.09$ & $0.18 \pm 0.06$ \\
\hline \multicolumn{11}{|l|}{ Experiment 7} \\
\hline Chronic saline & $0.70 \pm 0.13$ & $0.78 \pm 0.13$ & $0.73 \pm 0.10$ & $0.04 \pm 0.06$ & $0.01 \pm 0.05$ & $|| \pm 0.21$. & $3.09 \pm 0.58$ & $1.70 \pm 0.35$ & $0.42 \pm 0.06$ & $0.17 \pm 0.06$ \\
\hline Chronic fluoxetine & $0.64 \pm 0.10$ & $0.67 \pm 0.12$ & $0.69 \pm 0.12$ & $-0.01 \pm 0.08$ & $0.00 \pm 0.07$ & $2.20 \pm 0.43$ & $2.99 \pm 0.58$ & $2.40 \pm 0.58$ & $0.13 \pm 0.05$ & $0.01 \pm 0.04$ \\
\hline \multicolumn{11}{|l|}{ Phasic fear tests } \\
\hline \multicolumn{11}{|l|}{ Experiment 2} \\
\hline Acute saline & $0.68 \pm 0.12$ & $0.72 \pm 0.21$ & N/A & $-0.01 \pm 0.11$ & $\mathrm{~N} / \mathrm{A}$ & $0.55 \pm 0.11$ & $0.76 \pm 0.16$ & $N / A$ & $0.14 \pm 0.10$ & $N / A$ \\
\hline $\begin{array}{l}\text { Acute chlordiazepoxide } \\
(7.5 \mathrm{mg} / \mathrm{kg})^{\mathrm{b}}\end{array}$ & $0.57 \pm 0.13$ & $0.56 \pm 0.14$ & $\mathrm{~N} / \mathrm{A}$ & $-0.01 \pm 0.05$ & N/A & $0.39 \pm 0.13$ & $0.7 \mid \pm 0.25$ & N/A & $0.24 \pm 0.08$ & $N / A$ \\
\hline $\begin{array}{l}\text { Acute chlordiazepoxide } \\
(10 \mathrm{mg} / \mathrm{kg})\end{array}$ & $0.34 \pm 0.07$ & $0.40 \pm 0.07$ & N/A & $0.08 \pm 0.05$ & $\mathrm{~N} / \mathrm{A}$ & $0.20 \pm 0.04$ & $0.36 \pm 0.04$ & N/A & $0.29 \pm 0.11$ & $N / A$ \\
\hline \multicolumn{11}{|l|}{ Experiment 4} \\
\hline Acute saline & $0.62 \pm 0.12$ & $0.55 \pm 0.11$ & N/A & $-0.03 \pm 0.05$ & $N / A$ & $0.50 \pm 0.08$ & $1.16 \pm 0.36$ & $\mathrm{~N} / \mathrm{A}$ & $0.29 \pm 0.07$ & $N / A$ \\
\hline Acute buspirone & $0.81 \pm 0.24$ & $0.79 \pm 0.29$ & N/A & $-0.04 \pm 0.09$ & N/A & $1.12 \pm 0.24$ & $1.15 \pm 0.24$ & $N / A$ & $0.02 \pm 0.07$ & $N / A$ \\
\hline Acute fluoxetine & $0.61 \pm 0.07$ & $0.55 \pm 0.15$ & $N / A$ & $-0.03 \pm 0.07$ & $\mathrm{~N} / \mathrm{A}$ & $0.76 \pm 0.12$ & $1.43 \pm 0.31$ & $N / A$ & $0.23 \pm 0.04$ & $N / A$ \\
\hline \multicolumn{11}{|l|}{ Experiment 6} \\
\hline Chronic saline & $1.26 \pm 0.29$ & $1.29 \pm 0.47$ & $N / A$ & $-0.04 \pm 0.06$ & N/A & $1.42 \pm 0.35$ & $2.12 \pm 0.45$ & $N / A$ & $0.19 \pm 0.06$ & $N / A$ \\
\hline Chronic fluoxetine & $1.09 \pm 0.29$ & $1.07 \pm 0.28$ & $N / A$ & $-0.03 \pm 0.04$ & $N / A$ & $1.82 \pm 0.37$ & $2.76 \pm 0.69$ & $N / A$ & $0.14 \pm 0.07$ & $N / A$ \\
\hline
\end{tabular}


For many years, benzodiazepines have been the drug of choice for anxiety reduction, being partly supplanted more recently by monoamine reuptake inhibitors because of the greater potential for dependency and abuse with benzodiazepines. It is perhaps surprising then that the effect of benzodiazepines on phasic startle potentiation has been inconsistent, at least in human beings, with positive (Patrick et al, 1996; Bitsios et al, 1999; Riba et al, 2001; Graham et al, 2005) as well as negative (Baas et al, 2002; Scaife et al, 2005; Grillon et al, 2006) results being reported, and suggestions that the positive effects that have been reported were secondary to sedative effects (Baas et al, 2002) - a problem that may be especially pronounced when using absolute difference scores (ie, from trials without to those with the fear stimulus) rather than percent change scores (Grillon and Baas, 2002; Walker and Davis, 2002b).

Using percent change scores, we found that the benzodiazepine chlordiazepoxide did block sustained startle potentiation, but at the same dose $(10 \mathrm{mg} / \mathrm{kg})$ did not significantly influence phasic startle potentiation using either a standard test for phasic startle potentiation (Experiment 2), or the first trial of sustained fear testing as an alternative measure (Experiment 3). It is possible of course that a higher dose might have been effective. Doses above $10 \mathrm{mg} / \mathrm{kg}$ are generally avoided, however, due to the emergence of 'nonspecific' behavioral effects. In fact, even at $10 \mathrm{mg} / \mathrm{kg}$, baseline startle was reduced by approximately $50 \%$ in Experiment 2, which makes the preservation of phasic startle potentiation all the more remarkable. We do not believe that phasic startle potentiation is immune to benzodiazepine administration. Indeed, we ourselves, using a different protocol for phasic fear training (2 days of training with 10 pairings of a 3.7-s light and co-terminating footshock per day), have previously observed such effects (Davis, 1979; Walker and Davis, 2002a). However, these results, in which phasic and sustained startle potentiation data were measured after identical training and, in Experiment 3, in the same rats in the same test session in response to the same CS, seem especially compelling in showing a differential sensitivity. Indirect evidence for a greater sensitivity can be found in several other studies. For example, Guscott et al (2000) reported a statistically significant disruption of fear-potentiated startle to a 3.7-s CS by 10 but not $3 \mathrm{mg} / \mathrm{kg}$ chlordiazepoxide in rats trained and tested in different contexts, but significant effects on potentiated startle to the training context itself (sustained fear) at doses as low as $1 \mathrm{mg} / \mathrm{kg}$ (ie, 10 -fold difference). In human beings, Grillon et al (2006) reported that startle increases to an 8-s CS (phasic fear) were not affected by the benzodiazepine alprazolam, whereas startle increases to the experimental context (sustained fear) during the same test session were significantly reduced.

It is possible that phasic startle increases are simply more robust than sustained startle increases, and therefore less sensitive to disruption by any means (ie, a quantitative rather than qualitative difference). However, this explanation would not account for the opposite pattern of results (ie, a disruption of phasic but not sustained fear) that we observed for buspirone, which we turn to next.

Buspirone, known primarily as a $5 \mathrm{HT}_{1 \mathrm{~A}}$ partial agonist and dopamine D2 antagonist, potently disrupts phasic startle increases in rats when administered shortly before testing (Kehne et al, 1988; Mansbach and Geyer, 1988). In human beings, however, acute administration is not anxiolytic, and in a non-human primate model, does not reduce phasic fear (Winslow et al, 2007). For clinical anxiolysis, chronic administration is required (Jacobson et al, 1985; Goa and Ward, 1986; Goodman, 2004), suggesting that the mechanism of action for effects on phasic startle potentiation in rats (which may not involve serotonin -Davis et al (1988)) and for clinical efficacy in human beings may be different. In Experiment 4, we replicated the frequently reported effect observed in rats and, in Experiment 5, observed a quantitatively similar difference. In both experiments, an effect on baseline startle was also observed. These baseline effects frequently accompany (Mansbach and Geyer, 1988; Walker and Davis, 1997a) but are not required (Kehne et al, 1988; Melia and Davis, 1991) for buspirone effects on phasic fear.

In contrast, we saw no evidence for a disruption of sustained fear (Experiment 5). As always, it is conceivable that a higher dose might have been effective. However, we previously found that doses as low as $1.25 \mathrm{mg} / \mathrm{kg}$ ( $v s$ the $5 \mathrm{mg} / \mathrm{kg}$ used here) markedly disrupt phasic startle potentiation and that doses half that used here completely abolish the effect (Kehne et al, 1988). Note also that the effect on baseline startle provides a positive control for drug activity. Thus, we believe it unlikely that the failure to disrupt sustained startle potentiation was due to insufficient dosing. Thus, the effect of acute buspirone on sustained startle potentiation appears to reflect more accurately the effect of acute buspirone on clinical anxiety (no effect), than the effect of acute buspirone on phasic startle potentiation.

We should note that buspirone does disrupt lightenhanced startle, which is also a sustained increase in startle, albeit to an unconditioned stimulus (Walker and Davis, 1997a,b). Assuming that light-enhanced startle reflects anxiety, which we do, the results from that and this study suggest there may be more than one type of sustained fear (perhaps, for example, conditioned vs unconditioned) with different neural substrates or sensitivity to anxiolytic compounds.

As mentioned previously, chronic monoamine reuptake inhibitors have largely supplanted the use of benzodiazepines for anxiety reduction. Here, we evaluated the effect of acute and also chronic fluoxetine on phasic as well as sustained startle increases. Acute fluoxetine, which does not reduce anxiety in human beings, had no effect on phasic or sustained startle increases. In marked contrast, chronic fluoxetine did block sustained, but not phasic, increases. As indicated in Table 1, chronic fluoxetine also increased baseline startle responses in Experiment 7 and, to a lesser degree, in Experiment 6. These increases on baseline startle amplitude might be a result of actions in the spinal cord. Previous studies indicate that intrathecal administration of serotonin and other serotonin agonists increases startle amplitude, most likely by activating $5-\mathrm{HT}_{1 \mathrm{~A}}$ receptors on spinal motor neurons (Davis et al, 1980a, b; Commissaris and Davis, 1982). It is possible that fluoxetine is increasing startle through a similar mechanism in this study. Whatever the mechanism, we considered the possibility that these baseline increases could have occluded further fear-induced increases, without affecting fear itself. However, for several reasons, we do not believe this likely. First, the same rats 
did show potentiation to the first startle probe after CS onset (phasic fear) indicating that startle was not at a ceiling and that further increases were indeed possible. Moreover, we have found in other experiments that phasic startle increases are unaffected by much larger baseline elevations brought about by i.c.v. CRF infusions or systemic strychnine injections (Walker and Davis, 2002b). Finally, we found no evidence of a correlation between the effect on baseline startle and the effect on startle potentiation. For these analyses, and in keeping with the other analyses reported herein, we again used parametric (Pearson's) as well as non-parametric (Spearman's) techniques to correlate the baseline increase (expressed as the ratio between the post-conditioning preCS baseline and the pre-conditioning pre-CS baseline, or the log transformation of that ratio) with our ratio and log-transformed measures of sustained fear. Neither analysis (conducted on data from fluoxetine-treated rats only) found evidence for a relationship between these variables (Spearman's $r=-0.113, p=0.64$; Pearson's $r=-0.11$, $p=0.65)$. Overall then, we are confident that the abolition of sustained startle potentiation in Experiment 7 was not an artifact of the baseline startle increase.

As noted previously, the effect of chronic fluoxetine on sustained startle increases was in contrast to the effect on phasic startle increases, which were more variable. On the basis of the explicit test of phasic fear (Experiment 6), in which startle was elicited $3.2 \mathrm{~s}$ after CS onset, there was no disruption at all. However, when startle was elicited $19 \mathrm{~s}$ after CS onset (ie, to the first probe after onset of the sustained fear stimulus in Experiment 7), startle was significantly reduced but not abolished (as was the more sustained component of potentiation in these same rats).

Disruptions of sustained fear (ie, to context CSs) by chronic (Li et al, 2001) or sub-chronic (Santos et al, 2006) selective serotonin reuptake inhibitor (SSRI) administration have previously been reported. In one study (Burghardt et al, 2004), chronic administration of the SSRI citalopram beginning before training also disrupted freezing to a relatively short 20-s fear stimulus. Because freezing is generally found to persist well beyond CS offset, even when elicited by phasically presented fear stimuli (Quinn et al, 2002), it is likely that the fear response in that study was more sustained than phasic. In human beings, Grillon et al (2009a) found that chronic citalopram administration had no effect on startle potentiation to an 8-s fear stimulus, but did reduce the startle potentiation that occurred between stimulus presentations (a more sustained increase which may have reflected context fear). Thus, those results may reflect the same underlying time-dependent dissociation that we have observed in rats.

In interpreting the pattern of results observed across our experiments, it is perhaps relevant that phasic fear response is, in most cases, the stronger response. This could reflect the fact that, during conditioning, a greater number of shocks were experienced by the rats during the early part of the 8 -min CS. For example, using these training procedures for sustained fear, half of all footshocks occurred during the first minute of CS presentation (ie, at 3, 10, 20, and $60 \mathrm{~s}$ after CS onset). In developing this paradigm, we explored a number of different conditioning protocols, including one in which the ordering of shocks was reversed (ie, a mirror image of the shock schedule used here in which shock density was greater towards the end of the CS). Invariably however, we find that startle potentiation immediately following CS onset is greater than potentiation at later times after CS onset.

In any case, and as noted earlier, the greater magnitude of phasic compared to sustained startle potentiation does allow for the possibility that chlordiazepoxide and chronic fluoxetine disrupted sustained, but not phasic potentiation, simply because sustained startle potentiation was the weaker of the two responses. This makes the results obtained with buspirone-which disrupted the stronger phasic response and not the weaker sustained response - all the more important and highly suggestive of the possibility that phasic and sustained fear are fundamentally, not just quantitatively, different.

To our knowledge, these are the first explicit comparisons of drug effects on short- $v s$ longer-duration fear responses. On the basis of the compounds tested here, the results suggest that sustained fear paradigms may have greater predictive validity, and that the sustained fear itself may be more homologous to at least some types of clinical anxiety than phasic fear. In this regard, other findings by Grillon et al (2009b) are also relevant. In particular, they observed that startle potentiation to short-duration stimuli that have been paired with shock are no greater in post-traumatic stress (Grillon et al, 2009b) and panic disorder patients (Grillon et al, 2008) than in healthy controls, but that the startle responses that occur between stimulus presentations, which as noted earlier may reflect a more sustained type of anxiety to the less-predictive threat context, are greater (cf, Davis et al, 2010). These very interesting results lend support to the view that drugs that reduce sustained startle increases may be more clinically efficacious than those that preferentially reduce phasic startle increases.

The search for such compounds (ie, drugs that reduce sustained startle increases) may be aided by evidence that sustained fear, including fear responses to static contexts, is especially dependent on the BNST (eg, Walker and Davis, 1997b; Hammack et al, 2004; Sullivan et al, 2004; Waddell et al, 2006), whereas phasic fear responses are more dependent on the medial division of the CeA (cf, Walker et $a l, 2009 \mathrm{~b})$. Evidence supporting this view is derived primarily from lesion and inactivation studies, but is consistent with the results of unit recording and imaging studies in rats (Quirk et al, 1995) and human beings (Phelps et al, 2001), which have indicated only a transient activation of the amygdala by threat stimuli, but perhaps a more sustained activation of the BNST, the latter which may be exaggerated in subjects with high trait anxiety (Somerville et al, 2010). Perhaps, also relevant are recent results from Klumpers et al (2010), who reported a significant timedependent correlation between amygdala activation and startle potentiation in healthy human beings.

One notable feature of the BNST as well as the lateral CeA (which projects to the BNST), which distinguishes both from the medial CeA, is the abundance of so many different neuropeptide-positive cells and terminals (Roberts et al, 1982; Woodhams et al, 1983; Cassell et al, 1986; Ju et al, 1989; Shimada et al, 1989; Walter et al, 1991; Gray and Magnuson, 1992; Arluison et al, 1994). Because peptides often act for long periods of time, as we have found from local BNST infusions of either CRF (Liang et al, 1992) or CGRP (Sink et al, 2011), we believe that accelerated 
development of small molecule ligands for these receptors, and their evaluation in anxiety models such as the one used here, may be a prudent strategy for the development of new anxiolytic compounds with novel mechanisms of action. We have found, for example, that oral administration of the non-peptide CRF-R1 antagonist GSK876008 disrupts sustained, but not phasic startle increases to conditioned fear stimuli (Walker et al, 2009a, b), and also startle increases evoked directly by calcitonin gene-related peptide (CGRP) infusions into the BNST (Sink et al (2011) and unpublished observations), where receptors for both peptides are abundant (Skofitsch and Jacobowitz, 1985; Kruger et al, 1988; Chalmers et al, 1995; Christopoulos et al, 1995). We have also found that intra-BNST CGRP infusions increase anxiety measures in the plus maze, and that intra-BNST infusions of a CGRP antagonist decrease sustained startle increases produced by the predator odor 2,5-dihydro-2,4,5-trimethylthiazoline (Sink et al, 2011).

It is also worth noting that the BNST expresses several types of serotonin receptors, is densely innervated by serotonergic afferents (Freedman and Shi, 2001; Hammack et al, 2009) that in many cases project to CRF-positive BNST neurons (Phelix et al, 1992), and is especially enriched in serotonin transporters (Smith et al, 1999). These findings suggest that the BNST may be one site of action for SSRImediated anxiolysis. The recent observation that anxious temperament in monkeys is correlated with serotonin transporter availability in the BNST is consistent with this view (Oler et al, 2009).

\section{ACKNOWLEDGEMENTS}

This research was supported by National Institute of Mental Health Grants MH080330 (DW) and MH47840 (MD), an NARSAD Young Investigator Award to DW, an FACES (Facilitating Academic Careers in Engineering and Sciences) fellowship and an APA Predoctoral Fellowship (Diversity Neuroscience Program) to LM, the Science and Technology Center (The Center for Behavioral Neuroscience of the National Science Foundation under Agreement No. IBN-9876754), and the Yerkes Regional Primate Facility Base Grant.

\section{DISCLOSURE}

Dr Walker and Leigh Miles have no potential conflict of interest, nor any financial interests to disclose. Dr Davis received research support and an unrestricted gift from Astra-Zeneca and travel expenses and honoraria for lectures at AstraZeneca, Lundbeck, Sepracor Pharmaceuticals, International Behavioral Neuroscience Society, Society for Psychophysiological Research, The Society of Biological Psychiatry, Society for Neuroscience, American College of Neuropsychopharmacology, American Psychological Association, Japan Neuroscience Society, Cognitive Behavioral Society, Australian Neuroscience Society, NIMH, University of Maryland, University of Alabama, University of Bergen, Dartmouth College, UCSD, UC Irvine, Vanderbilt University, Harvard University, Yale University, MIT, Tufts University, Toyama University, and Uniformed Services University.

\section{REFERENCES}

Arluison M, Brochier G, Vankova M, Leviel V, Villalobos J, Tramu G (1994). Demonstration of peptidergic afferents to the bed nucleus of the stria terminalis using local injections of colchicine. A combined immunohistochemical and retrograde tracing study. Brain Res Bull 34: 319-337.

Baas JM, Grillon C, Bocker KB, Brack AA, Morgan III CA, Kenemans JL et al (2002). Benzodiazepines have no effect on fear-potentiated startle in humans. Psychopharmacology (Berl) 161: 233-247.

Bitsios P, Philpott A, Langley RW, Bradshaw CM, Szabadi E (1999). Comparison of the effects of diazepam on the fear-potentiated startle reflex and the fear-inhibited light reflex in man. J Psychopharmacol 13: 226-234.

Burghardt NS, Sullivan GM, McEwen BS, Gorman JM, LeDoux JE (2004). The selective serotonin reuptake inhibitor citalopram increases fear after acute treatment but reduces fear with chronic treatment: a comparison with tianeptine. Biol Psychiatry 55: 1171-1178.

Cassell MD, Gray TS, Kiss JZ (1986). Neuronal architecture in the rat central nucleus of the amygdala: a cytological, hodological, and immunocytochemical study. J Comp Neurol 246: 478-499.

Chalmers DT, Lovenberg TW, De Souza EB (1995). Localization of novel corticotropin-releasing factor receptor (CRF2) mRNA expression to specific subcortical nuclei in rat brain: comparison with CRF1 receptor mRNA expression. J Neurosci 15: 6340-6350.

Christopoulos G, Paxinos G, Huang XF, Beaumont K, Toga AW, Sexton PM (1995). Comparative distribution of receptors for amylin and the related peptides calcitonin gene related peptide and calcitonin in rat and monkey brain. Can J Physiol Pharmacol 73: 1037-1041.

Commissaris RL, Davis M (1982). Opposite effects of $\mathrm{N}, \mathrm{N}$ dimethyltryptamine (DMT) and 5-methoxy- $n, n$-dimethyltryptamine (5-MeODMT) on acoustic startle: spinal $v s$ brain sites of action. Neurosci Biobehav Rev 6: 515-520.

Davis M (1979). Diazepam and flurazepam: effects on conditioned fear as measured with the potentiated startle paradigm. Psychopharmacology (Berl) 62: 1-7.

Davis M (1986). Pharmacological and anatomical analysis of fear conditioning using the fear-potentiated startle paradigm. Behav Neurosci 100: 814-824.

Davis M (2006). Neural systems involved in fear and anxiety measured with fear-potentiated startle. Am Psychol 61: 741-756.

Davis M, Astrachan DI, Gendelman PM, Gendelman DS (1980a). 5-Methoxy- $N, N$-dimethyltryptamine: spinal cord and brainstem mediation of excitatory effects on acoustic startle. Psychopharmacology (Berl) 70: 123-130.

Davis M, Cassella JV, Kehne JH (1988). Serotonin does not mediate anxiolytic effects of buspirone in the fear-potentiated startle paradigm: comparison with 8-OH-DPAT and ipsapirone. Psychopharmacology (Berl) 94: 14-20.

Davis M, Strachan DI, Kass E (1980b). Excitatory and inhibitory effects of serotonin on sensorimotor reactivity measured with acoustic startle. Science 209: 521-23.

Davis M, Walker DL, Miles L, Grillon C (2010). Phasic vs sustained fear in rats and humans: role of the extended amygdala in fear $v s$ anxiety. Neuropsychopharmacology 35: 105-135.

Freedman LJ, Shi C (2001). Monoaminergic innervation of the macaque extended amygdala. Neuroscience 104: 1067-1084.

Gewirtz JC, McNish KA, Davis M (1998). Lesions of the bed nucleus of the stria terminalis block sensitization of the acoustic startle reflex produced by repeated stress, but not fear-potentiated startle. Prog Neuropsychopharmacol Biol Psychiatry 22: 625-648.

Goa KL, Ward A (1986). Buspirone. A preliminary review of its pharmacological properties and therapeutic efficacy as an anxiolytic. Drugs 32: 114-129. 
Goodman WK (2004). Selecting pharmacotherapy for generalized anxiety disorder. J Clin Psychiatry 65(Suppl 13): 8-13.

Graham SJ, Scaife JC, Langley RW, Bradshaw CM, Szabadi E, Xi L et al (2005). Effects of lorazepam on fear-potentiated startle responses in man. J Psychopharmacol 19: 249-258.

Gray TS, Magnuson DJ (1992). Peptide immunoreactive neurons in the amygdala and the bed nucleus of the stria terminalis project to the midbrain central gray in the rat. Peptides 13: $451-460$.

Grillon C, Baas JM (2002). Comments on the use of the startle reflex in psychopharmacological challenges: impact of baseline startle on measurement of fear-potentiated startle. Psychopharmacology (Berl) 164: 236-238.

Grillon C, Baas JM, Pine DS, Lissek S, Lawley M, Ellis V et al (2006). The benzodiazepine alprazolam dissociates contextual fear from cued fear in humans as assessed by fear-potentiated startle. Biol Psychiatry 60: 760-766.

Grillon C, Chavis C, Covington MF, Pine DS (2009a). Two-week treatment with the selective serotonin reuptake inhibitor citalopram reduces contextual anxiety but not cued fear in healthy volunteers: a fear-potentiated startle study. Neuropsychopharmacology 34: 964-971.

Grillon C, Lissek S, Rabin S, McDowell D, Dvir S, Pine DS (2008). Increased anxiety during anticipation of unpredictable but not predictable aversive stimuli as a psychophysiologic marker of panic disorder. Am J Psychiatry 165: 898-904.

Grillon C, Pine DS, Lissek S, Rabin S, Bonne O, Vythilingam M (2009b). Increased anxiety during anticipation of unpredictable aversive stimuli in posttraumatic stress disorder but not in generalized anxiety disorder. Biol Psychiatry 66: 47-53.

Guscott MR, Cook GP, Bristow LJ (2000). Contextual fear conditioning and baseline startle responses in the rat fearpotentiated startle test: a comparison of benzodiazepine/gammaaminobutyric acid-A receptor agonists. Behav Pharmacol 11: 495-504.

Hammack SE, Guo JD, Hazra R, Dabrowska J, Myers KM, Rainnie DG (2009). The response of neurons in the bed nucleus of the stria terminalis to serotonin: implications for anxiety. Prog Neuropsychopharmacol Biol Psychiatry 33: 1309-1320.

Hammack SE, Richey KJ, Watkins LR, Maier SF (2004). Chemical lesion of the bed nucleus of the stria terminalis blocks the behavioral consequences of uncontrollable stress. Behav Neurosci 118: 443-448.

Hitchcock JM, Davis M (1991). Efferent pathway of the amygdala involved in conditioned fear as measured with the fearpotentiated startle paradigm. Behav Neurosci 105: 826-842.

Jacobson AF, Dominguez RA, Goldstein BJ, Steinbook RM (1985). Comparison of buspirone and diazepam in generalized anxiety disorder. Pharmacotherapy 5: 290-296.

Ju G, Swanson LW, Simerly RB (1989). Studies on the cellular architecture of the bed nuclei of the stria terminalis in the rat: II. Chemoarchitecture. J Comp Neurol 280: 603-621.

Keene ON (1995). The log transformation is special. Stat Med 14: 811-819.

Kehne JH, Cassella JV, Davis M (1988). Anxiolytic effects of buspirone and gepirone in the fear-potentiated startle paradigm. Psychopharmacology (Berl) 94: 8-13.

Klumpers F, Raemaekers MA, Ruigrok AN, Hermans EJ, Kenemans JL, Baas JM (2010). Prefrontal mechanisms of fear reduction after threat offset. Biol Psychiatry 68: 1031-1038.

Kruger L, Mantyh PW, Sternini C, Brecha NC, Mantyh CR (1988). Calcitonin gene-related peptide (CGRP) in the rat central nervous system: patterns of immunoreactivity and receptor binding sites. Brain Res 463: 223-244.

Lee Y, Davis M (1997). Role of the hippocampus, the bed nucleus of the stria terminalis, and the amygdala in the excitatory effect of corticotropin-releasing hormone on the acoustic startle reflex. J Neurosci 17: 6434-6446.
Li XB, Inoue T, Hashimoto S, Koyama T (2001). Effect of chronic administration of flesinoxan and fluvoxamine on freezing behavior induced by conditioned fear. Eur J Pharmacol 425: 43-50.

Liang KC, Melia KR, Campeau S, Falls WA, Miserendino MJ, Davis M (1992). Lesions of the central nucleus of the amygdala, but not the paraventricular nucleus of the hypothalamus, block the excitatory effects of corticotropin-releasing factor on the acoustic startle reflex. J Neurosci 12: 2313-2320.

Mansbach RS, Geyer MA (1988). Blockade of potentiated startle responding in rats by 5-hydroxytryptamine1A receptor ligands. Eur J Pharmacol 156: 375-383.

McNish KA, Gewirtz JC, Davis M (1997). Evidence of contextual fear after lesions of the hippocampus: a disruption of freezing but not fear-potentiated startle. J Neurosci 17: 9353-9360.

Melia KR, Davis M (1991). Effects of septal lesions on fearpotentiated startle, and on the anxiolytic effects of buspirone and diazepam. Physiol Behav 49: 603-611.

Meloni EG, Davis M (1999). Muscimol in the deep layers of the superior colliculus/mesencephalic reticular formation blocks expression but not acquisition of fear-potentiated startle in rats. Behav Neurosci 113: 1152-1160.

Oler JA, Fox AS, Shelton SE, Christian BT, Murali D, Oakes TR et al (2009). Serotonin transporter availability in the amygdala and bed nucleus of the stria terminalis predicts anxious temperament and brain glucose metabolic activity. $J$ Neurosci 29: 9961-9966.

Patrick CJ, Berthot BD, Moore JD (1996). Diazepam blocks fearpotentiated startle in humans. J Abnorm Psychol 105: 89-96.

Phelix CF, Liposits Z, Paull WK (1992). Serotonin-CRF interaction in the bed nucleus of the stria terminalis: a light microscopic double-label immunocytochemical analysis. Brain Res Bull 28: 943-948.

Phelps EA, O’Connor KJ, Gatenby JC, Gore JC, Grillon C, Davis M (2001). Activation of the left amygdala to a cognitive representation of fear. Nat Neurosci 4: 437-441.

Quinn JJ, Oommen SS, Morrison GE, Fanselow MS (2002). Posttraining excitotoxic lesions of the dorsal hippocampus attenuate forward trace, backward trace, and delay fear conditioning in a temporally specific manner. Hippocampus 12: 495-504.

Quirk GJ, Repa C, LeDoux JE (1995). Fear conditioning enhances short-latency auditory responses of lateral amygdala neurons: parallel recordings in the freely behaving rat. Neuron 15: 1029-1039.

Riba J, Rodriguez-Fornells A, Urbano G, Morte A, Antonijoan R, Barbanoj MJ (2001). Differential effects of alprazolam on the baseline and fear-potentiated startle reflex in humans: a doseresponse study. Psychopharmacology (Berl) 157: 358-367.

Roberts GW, Woodhams PL, Polak JM, Crow TJ (1982). Distribution of neuropeptides in the limbic system of the rat: the amygdaloid complex. Neuroscience 7: 99-131.

Rosen JB, Hitchcock JM, Sananes CB, Miserendino MJ, Davis M (1991). A direct projection from the central nucleus of the amygdala to the acoustic startle pathway: anterograde and retrograde tracing studies. Behav Neurosci 105: 817-825.

Santos JM, Martinez RC, Brandao ML (2006). Effects of acute and subchronic treatments with fluoxetine and desipramine on the memory of fear in moderate and high-intensity contextual conditioning. Eur J Pharmacol 542: 121-128.

Scaife JC, Langley RW, Bradshaw CM, Szabadi E (2005). Diazepam suppresses the acquisition but not the expression of 'fearpotentiation' of the acoustic startle response in man. J Psychopharmacol 19: 347-356.

Shimada S, Inagaki S, Kubota Y, Ogawa N, Shibasaki T, Takagi H (1989). Coexistence of peptides (corticotropin releasing factor/ neurotensin and substance $\mathrm{P} /$ somatostatin) in the bed nucleus of the stria terminalis and central amygdaloid nucleus of the rat. Neuroscience 30: 377-383. 
Sink KS, Walker DL, Yang Y, Davis M (2011). Calcitonin gene-related peptide in the bed nucleus of the stria terminalis produces an anxiety-like pattern of behavior and increases neural activation in anxiety-related structures. J Neurosci 31: 1802-1810.

Skofitsch G, Jacobowitz DM (1985). Autoradiographic distribution of ${ }^{125} \mathrm{I}$ calcitonin gene-related peptide binding sites in the rat central nervous system. Peptides 6: 975-986.

Smith HR, Daunais JB, Nader MA, Porrino LJ (1999). Distribution of $\left[{ }^{3} \mathrm{H}\right]$ citalopram binding sites in the nonhuman primate brain. Ann NY Acad Sci 877: 700-702.

Somerville LH, Whalen PJ, Kelley WM (2010). Human bed nucleus of the stria terminalis indexes hypervigilant threat monitoring. Biol Psychiatry 68: 416-424.

Sullivan GM, Apergis J, Bush DE, Johnson LR, Hou M, Ledoux JE (2004). Lesions in the bed nucleus of the stria terminalis disrupt corticosterone and freezing responses elicited by a contextual but not by a specific cue-conditioned fear stimulus. Neuroscience 128: 7-14.

Waddell J, Morris RW, Bouton ME (2006). Effects of bed nucleus of the stria terminalis lesions on conditioned anxiety: aversive conditioning with long-duration conditional stimuli and reinstatement of extinguished fear. Behav Neurosci 120: 324-336.

Walker D, Yang Y, Ratti E, Corsi M, Trist D, Davis M (2009a). Differential effects of the CRF-R1 antagonist GSK876008 on fearpotentiated, light- and CRF-enhanced startle suggest preferential involvement in sustained $v s$ phasic threat responses. Neuropsychopharmacology 34: 1533-1542.

Walker DL, Davis M (1997a). Anxiogenic effects of high illumination levels assessed with the acoustic startle response in rats. Biol Psychiatry 42: 461-471.
Walker DL, Davis M (1997b). Double dissociation between the involvement of the bed nucleus of the stria terminalis and the central nucleus of the amygdala in startle increases produced by conditioned $v s$ unconditioned fear. J Neurosci 17: 9375-9383.

Walker DL, Davis M (2002a). Light-enhanced startle: further pharmacological and behavioral characterization. Psychopharmacology (Berl) 159: 304-310.

Walker DL, Davis M (2002b). Quantifying fear potentiated startle using absolute vs proportional increase scoring methods: implications for the neurocircuitry of fear and anxiety. Psychopharmacology (Berl) 164: 318-328.

Walker DL, Miles LA, Davis M (2009b). Selective participation of the bed nucleus of the stria terminalis and CRF in sustained anxiety-like vs phasic fear-like responses. Prog Neuropsychopharmacol Biol Psychiatry 33: 1291-1308.

Walter A, Mai JK, Lanta L, Gorcs T (1991). Differential distribution of immunohistochemical markers in the bed nucleus of the stria terminalis in the human brain. J Chem Neuroanat 4: 281-298.

Winslow JT, Noble PL, Davis M (2007). Modulation of fearpotentiated startle and vocalizations in juvenile rhesus monkeys by morphine, diazepam, and buspirone. Biol Psychiatry 61: 389-395.

Woodhams PL, Roberts GW, Polak JM, Crow TJ (1983). Distribution of neuropeptides in the limbic system of the rat: the bed nucleus of the stria terminalis, septum and preoptic area. Neuroscience 8: 677-703.

Zhao Z, Davis M (2004). Fear-potentiated startle in rats is mediated by neurons in the deep layers of the superior colliculus/deep mesencephalic nucleus of the rostral midbrain through the glutamate non-NMDA receptors. J Neurosci 24: 10326-10334. 